\title{
ASPECTOS DA SOCIEDADE ENFATIZANDO A VIOLÊNCIA NO COTIDIANO DAS CRIANÇAS E ADOLESCENTES
}

\author{
Ana Claudia Santos de Oliveira ${ }^{1}$ \\ Carlos Bispo de Jesus Filho ${ }^{2}$
}

\begin{abstract}
Resumo
Este artigo discute conceitos da violência abordando tópicos sobre passado e presente da violência no Brasil; a sociedade de consumo; a violência contra crianças e adolescentes; e as causas e consequências da violência na formação social. A metodologia da pesquisa foi a revisão bibliográfica em livros, artigos e dissertações na internet entre outras fontes. Conclui-se que No Brasil a violência é a expressão mais importante do impacto desorganizador que a desigualdade social e o patrimonialismo, junto com a explosão de expectativas associadas ao individualismo e ao consumismo sobre o conjunto da sociedade. Essa desorganização chega a impossibilitar a rotina diária das crianças e adolescente não só dos grupos mais pobres como das classes média e alta.
\end{abstract}

Palavras Chaves: Violência. Crianças. Adolescentes

\begin{abstract}
This article discusses concepts of violence, addressing topics about the past and present of violence in Brazil; the consumer society; violence against children and adolescents; and the causes and consequences of violence in social formation. The research methodology was a bibliographic review of books, articles and dissertations on the internet, among other sources. It is concluded that in Brazil, violence is the most important expression of the disorganizing impact that social inequality and patrimonialism, together with the explosion of expectations associated with individualism and consumerism on society as a whole. This disorganization makes it impossible for the daily routine of children and adolescents, not only of the poorest groups, but also of the middle and upper classes.
\end{abstract}

Keywords: Violence. Kids. Teenagers

\section{INTRODUÇÃO}

A realização desta pesquisa surge mediante a necessidade de refletir sobre uma visão ampla acerca das situações de violências nas escolas públicas em um município do interior do Recôncavo Baiano. Pois se pretende refletir e discutir possíveis medidas e estratégicas para a superação da violência nas escolas.

O homem, sendo um ser inerentemente social, visto que se constitui a partir das ações conjugadas com outros homens, necessita refletir, questionar a sociedade

\footnotetext{
1 Mestra em Ciências da Educação pela Faculdade Interamericana de Ciências Sociais-FICS. Especialista em Psicopedagogia Clinica e Institucional pela Faculdade Batista da Bahia-Especialista em História da África e Cultura Indígena pela Universidade Federal do Recôncavo UFRB. Especialista em Gestão e coordenação pela Faculdade Batista - Bahia. Graduada em pedagogia pela Universidade Estadual de Feira de Santana- UEFS. Professora da Rede Municipal de Santo Amaro da Purificação e da Rede Municipal de Saubara Bahia. Email: anaclaudiasantos38@yahoo.com.br

2 Doutorando em Ciências da Educação pela Faculdade Interamericana de Ciências Sociais - FICS. Mestre em Ciências da Educação pela Faculdade Interamericana de Ciências Sociais - FICS. Bacharel em Psicologia pela Faculdade da Cidade. Diretor de Departamento na rede municipal de São Francisco do Conde - Ba. Email: malazarth@yahoo.com.br
} 
que habita, mas que nem sempre atua. A vida social é repleta de relações contraditórias que muitas vezes são responsáveis pelas desigualdades sociais que tem como filha a violência.

A violência invadiu todas as esferas e ela está presente na relação com as pessoas, logo a sociedade se preocupa em refletir sobre a paz. Infelizmente, as escolas não conseguem escapar dessa realidade. Espaço privilegiado de democratização e de construção da cidadania, e a escola têm se tornado refém da cultura da violência, pois:

\begin{abstract}
A violência instaurou-se nas escolas como um fenômeno crescente, presente em especial nas que se localizam nas áreas urbanas, alternando o comportamento dos jovens, que expressam a sua frustração sobre a família, o trabalho, a escola e a comunidade (YUS, 2002, p. 17).
\end{abstract}

Os meios de comunicação audiovisual, não raras vezes retratam acontecimentos violentos protagonizados pelos alunos nas escolas. A violação dos direitos humanos tem como consequências diretas à evasão escolar, geração de mais violência e perda de cidadania De fato, "inverteram-se os papéis; os métodos violentos de alguns professores eram tradicionalmente mais frequentes no mundo escolar: castigo físico, humilhações verbais" (FERMOSO, 1998 p.85).

Sabe-se que passamos por uma crise e que o caminho mais curto para tentar vencê-la é sem dúvida a escola, mas não se deve esquecer-se de trabalhar respeitando sempre suas características individuais, conhecendo-os e a partir disso, decidir o tipo de ajuda pedagógica que será oferecida e interagir com essa ajuda.

A escola deve ser vista como extensão do lar. Com sua missão de ensinar, formar, informar e construir uma sociedade mais solidária, justa, humana e, sobretudo, comprometida com o bem estar do cidadão e com o desenvolvimento do estado.

\title{
Conceituando Violência
}

A violência tornou-se uma adversidade de saúde pública no em nosso país e também no mundo à medida que pode ser apresentada, como responsável por grande número de mortes, de adoecimentos e de profundas sequelas na população, nos mais variados aspectos. Em larga escala e se tornando algo cada vez mais comum, vivencia-se no cotidiano situações de violências, como uma tentativa de assalto, uma agressão física ou a invasão diária de cenas violentas por meio dos 
telejornais, tornando os indivíduos prisioneiros do medo, insegurança, onde cada um busca se proteger da melhor forma possível e a sua maneira.

Ao falar em violência, a mesma possui um amplo significado, a medida que assume sempre o mesmo papel em diferentes contextos. Sendo avaliada como um problema de saúde pública, segundo a OMS e assim, acarretando grandes e negativos acontecimentos na vida de todos. Neste sentido, a violência é definida como:

O uso intencional da força ou do poder, real ou em ameaça, contra si próprio, contra outra pessoa, ou contra um grupo ou uma comunidade, que resulte ou tenha possibilidade de resultar em lesão, morte, dano psicológico, deficiência de desenvolvimento ou privação (KRUG et al, 2002).

É possível citar a violência entre as pessoas no geral, violência contra os animais, violência ao patrimônio público, e entre uma grande diversidade existente. Todas estas configurando algum tipo de crime previsto em lei contra o estado ou o individuo, propicio a alguma punição, principalmente a de passar um determinado tempo recluso. Ou seja, preso seja numa pequena cadeia ou penitenciaria juntamente com demais pessoas do mesmo nível ou de alta periculosidade, pois:

\begin{abstract}
A violência é compreendida como todas as violações dos direitos civis, como a vida, a propriedade, a liberdade de ir e vir, de consciência e de culto. Políticos, como o direito a votar e a ser votado, ter participação política. Sociais, como habitação, saúde, educação, segurança. Econômicos, como emprego e salário. Culturais, como o direito de manter e manifestar sua própria cultura (CECCON, 2009, p. 36).
\end{abstract}

Não existe uma definição que contemple a todos os caracterizados e ligados aos mesmos, à única certeza que é possível compreender é que são ações sejam elas: verbais ou físicas que resultam em consequências negativas, já que vistas e inaceitáveis a um conjunto de normas e regras que não condizem para a vivência e permanência em sociedade com demais pessoas que não cometem qualquer ato interpretado como violência e de qualquer gênero. Um dos conceitos sobre violência pode ser caracterizada como:

Ação ou efeito de violentar, de empregar força física (contra alguém ou algo) ou intimidação moral contra (alguém); ato violento, crueldade, força. No aspecto jurídico, define o termo como o constrangimento físico ou moral exercido sobre alguém, para obrigá-lo a submeter-se à vontade de outrem; coação (HOUAISS, 2001, p.105).

As diversas formas que se manifestam a violência, que cada vez mais vemos com uma grande frequência e referindo principalmente como violação da lei penal, como assassinato, sequestros, roubos e outros tipos de crime contra a pessoa ou contra o patrimônio, formam um conjunto que se convencionou chamar de violência 
urbana, porque se manifesta principalmente no espaço das grandes cidades. A complexidade da violência precisa ser observada e cuidadosamente compreendida, ela "aparece na polissemia do seu conceito. Deve-se tomar cuidado ao expor um conceito sobre violência, pois ele pode ter vários sentidos, como: ataque físico, uso da força física ou até mesmo ameaça" (HAYEK, 2009, p. 57).

Ainda assim, vem a ser de suma importância, citar também as diferentes formas de violência que acontecem e vem ganhando espaço no campo rural, um lugar que há muito tempo não vem sendo visto com calmo, tranquilo e tido como ideal para uma família que busca fugir das constantes turbulências da cidade grande viver. Ações ou atos de violência precisam ser combatidos e minimizados, pois:

\begin{abstract}
Violência é um ato de brutalidade, sevícia e abuso físico e/ou psíquico contra alguém e caracteriza relações intersubjetivas e socais definidas pela opressão, intimação, pelo medo e pelo terror, Chauí acrescenta que a violência se opõe à ética pelo simples e fundamental motivo de que se trata de seres racionais e sensíveis, dotados de linguagem e de liberdade, isto é, não são coisas. Portanto, a ética é inseparável do sujeito racional, livre, responsável, voluntário (MODENA, 2016, p.19)
\end{abstract}

Percebe-se a violência contra o ser humano seja na zona urbana, seja na zona rural, como um fenômeno cada vez mais crescente e assustador, sendo que se encontra de forma tão descontrolada e compulsória, que até para os órgãos competentes em segurança, vem se tornando cada vez mais complicado, difícil e árduo resolver tantas situações, encontrar e punir os autores das mais simples até as mais absurdas e cruéis contra o próprio ser humano.

Ao citar a violência já que estamos falando de forma extensa, pode-se citar também a mesma que vem sendo cometida diariamente, e que não se encontra distante do fato cotidiano, a violência contra os animais, onde muitas pessoas em requintes de crueldades matam, mutilam, maltratam seres indefesos e que buscam somente ser companhia e dar carinho e que gostam de receber o mesmo. Mas algo que não está acontecendo em muitos lugares de forma crescente as pessoas de maneira geral está se tornando cada vez mais intolerantes, frias e desacreditadas da vida, da justiça e até em religião muitos atribuem a falta de fé. Vale destacar que:

Além do conceito de violência, há o problema das formas de violência. Sua classificação depende dos critérios escolhidos, das evidências da realidade empírica, dos modos de combater a violência e de outras modalidades. O conceito de violência é tão amplo que dificilmente as classificações abrangem todas as formas. Apesar disso, a tipologia de violência pode ser útil para visualizar suas modalidades (lbid., p. 11). 
Existem diversas nomenclaturas para violência a depender do ambiente na qual a mesma se instala e acontece, assim temos: Violência criminal; Violência coletiva; Violência institucional; Violência interpessoal que de acordo com a OMS se subdivide e pode ser: intrafamiliar e comunitária, violência auto infligida; violência cultural que pode ser destacada os dois tipos mais graves em nosso cotidiano, portanto, mais frequentes: a violência de gênero e violência racial/étnica; violência física; violência sexual; violência psicológica; negligência, abandono e privação de cuidados. Observa-se que:

A violência configura-se como um dispositivo de controle aberto e contínuo,
ou seja, a relação social caracterizada pelo uso real ou virtual da coerção,
que impede o reconhecimento do outro, pessoa, classe, gênero ou raça,
mediante o uso da força ou da coerção, provocando algum tipo de dano,
configurando o oposto das possibilidades da sociedade democrática
contemporânea (DOS SANTOS BARROS, C. R.; SCHRAIBER, 2017, p. 62).

Ao falar em violência, suas definições abordam-se também implicações frente a uma sociedade que vem se tornando cada vez mais refém da mesma, uma vez que a falta de segurança e de certa forma as autoridades competentes não estão tendo força suficiente para combater tudo isto. Faz-se necessário compreender os principais fatores que contribuem para o surgimento desta nos mais variados ambientes sociais, bem como o que ocasiona duvidas e questionamentos das populações, já que vemos com grande frequência crianças, jovens e adolescentes vitimas de situações em que muitas vezes acabam por perder suas vidas.

Citando de forma direta a policia, por exemplo, em que constantemente se veem em diversas polemicas e despertando muitas revoltas entre todos, já que em muitos casos são apontados com autores de crimes destruindo famílias, julgando jovens por aparências e quando se vai apurar muitos destes nunca tiveram qualquer tipo de indicio de cometer delitos ou violência contra alguém e buscam de uma forma ou outra se camuflar, tentando forjar inverdades.

Assim, pode ser um dos pontos que se pode observar, além dos demais, onde a violência cresce e onde os que deveriam ajudar e proteger a população acabam por contribuir para o crescimento a medida que abusam da autoridade, comete atos sem justiça, muitas vezes nenhuma punição de forma concreta acontece e gera em todos insatisfação e uma negatividade crescente, criando assim na sociedade pessoas que desacreditam de tudo aquilo que julgavam ser o certo e acontecem novos casos de criminalidade, fruto de coisas que deveriam ser 0 exemplo e infelizmente caminham em sentido contrario. 


\section{Passado e Presente da Violência no Brasil}

O Brasil, ao decorrer de toda a sua historia, foi marcado por grandes, significativos e inesquecíveis conflitos de maneira negativa, frutos de disputas, das mais variadas formas, e geralmente de cunho politico, gerando controvérsias, faros questionáveis e lembranças para muitos dolorosos e impactantes que nem mesmo $o$ tempo foi capaz de resolver.

Pode-se perceber a violência em grande destaque, nascida a partir de sentimentos de rancor, ódio e raiva e que diretamente influenciou grupos de pessoas em diferentes tempos e atualmente de certa maneira continua a influenciar a medida que se presencia isso no cotidiano. E mais uma vez, tudo tem inicio a partir de indivíduos que entram para politica, defendem uma linha de pensamento e hoje com os diversos tipos de comunicação influenciam a população seja de uma cidade, estado ou país, que se permitem impregnar por causas que não são suas, problemas que poderiam ser evitados e através do dialogo e não por embate que muitas vezes tem um fim desagradável, trágico e complicado de se mudar esse quadro.

A sociedade brasileira tradicional, a partir de um complexo equilíbrio de hierarquia e individualismos, se desenvolveu, associado a um sistema de trocas, reciprocidade na desigualdade e patronagem ${ }^{3}$, o uso da violência, mais ou menos legítimo, por parte de atores sociais bem definidos. Neste cenário social:

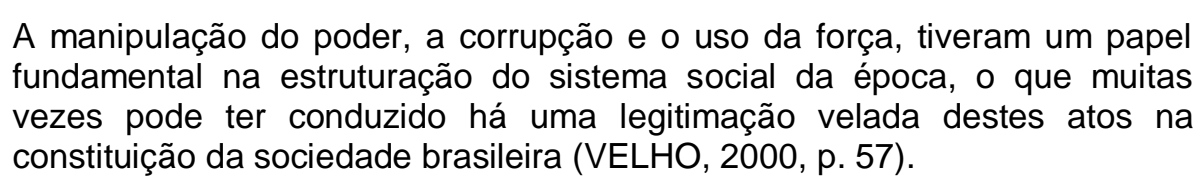

Nessa lógica, a violência encontra-se reificada ${ }^{4}$ quanto ao poder, o sistema, ao capitalismo, o sentimento de liderança, entre outros, como um elemento que é visto de modo isolado, individualizado, da sociedade na qual ela faz sua aparição. Tudo isso como se a violência e o violento fossem acidentes ou anomalias que um determinado tipo de sistema provoca e não uma possibilidade real e concreta de manifestação da sociedade brasileira.

Ao falar em política de defesa dos direitos humanos, o Brasil é considerado como um dos países mais avançados; que participou de vários tratados

\footnotetext{
${ }^{3}$ Apoio moral ou material oferecido por alguém ou por uma organização.

${ }^{4}$ É a desnaturalização daquilo que se tem como conceito e contextualizá-lo como algo isolado.
} 
internacionais; implantou leis que têm sido promulgadas e a Constituição Brasileira é considerada uma das que mais assegura direitos às pessoas, às crianças e aos adolescentes, onde em artigo 227 da Constituição visa a garantir às crianças e aos adolescentes, com absoluta prioridade, alimentação, educação, proteção, saúde, segurança.

Vivemos em um país, onde as leis são bem estruturadas, mas em sua maioria não funciona, pela corrupção, hipocrisia e as desigualdades sociais são predominantemente dominantes, sendo que a lei que mais funciona é a de quem tem mais a oferecer, principalmente em questões financeiras. Sendo, portanto, que as leis supracitadas na prática, não funcionam de forma que se deveria, e muita coisa fica apenas no papel, e em muitos casos crimes que já se passaram muitos anos, simplesmente não acontecem mais nenhum tipo de punição, pois o que está prescrito não vem sendo cumpridos por corrupção. E paralelamente ao processo de:

\begin{abstract}
Elaboração e implementação das políticas sociais destinadas ao atendimento à criança e ao adolescente, o período de redemocratização se caracterizou pela reforma administrativa do Estado, que envolveu a descentralização e a municipalização de políticas públicas e, também, a institucionalização do controle social, com a criação de conselhos e espaços públicos de interlocução e cogestão política, bem como a mobilização e participação social de diversos setores da sociedade civil (RUS PEREZ e PASSONE, 2010, p.665).
\end{abstract}

Há muito tempo inúmeras medidas vêm sendo tomadas para diminuir os episódios de violência, mais precisamente mais de meio século aproximadamente. Entre elas temos a assinatura de tratados; promulgação de leis; implantação do Estatuto da Criança e do Adolescente $(E C A)^{5}$; criação de varas; delegacias especializadas; escritórios de defensoria; conselhos municipais e tutelares; comissões nacionais, estaduais e municipais de defesa de direitos; programas de proteção às testemunhas; combate à pobreza, às desigualdades sociais, ao tráfico de drogas, ao contrabando de armas, à impunidade, à corrupção; desarmamento da população, e, também, das crianças por seus brinquedos marciais; construção de centros de ressocialização para "recuperar" infratores adolescentes com a Fundação

\footnotetext{
${ }^{5}$ Conjunto de normas do ordenamento jurídico brasileiro que tem como objetivo a proteção integral da criança e do adolescente, aplicando medidas e expedindo encaminhamentos para o juiz. É o marco legal e regulatório dos direitos humanos de crianças e adolescentes.
} 
Nacional do Bem-Estar do Menor (FUNABEM) e a Fundação Estadual para o Bem Estar do Menor (FEBEM) ${ }^{7}$; delegacias; penitenciárias; presídios de segurança máxima.

Além das leis, instituições e ações acima mencionadas tem também o trabalho de conscientização da população; distribuição de cartilhas com recomendações para evitar os diferentes tipos de violência; e a criação de ONGs que se dedicam a promover a paz. Pode-se salientar que:

\begin{abstract}
O Sistema de Garantia de Direitos, que representa o arcabouço da política de atendimento à infância e adolescência no Brasil, tem sido considerado um conjunto de instituições, organizações, entidades, programas e serviços de atendimento infanto-juvenil e familiar, os quais devem atuar de forma articulada e integrada, nos moldes previstos pelo ECA e pela Constituição Federal, com o intuito de efetivamente implementar a Doutrina da Proteção Integral por meio da política nacional de atendimento infanto-juvenil (RUS PEREZ e PASSONE, 2010, p.667).
\end{abstract}

Assim, ao falar no Brasil e os seus retrospectos percebe-se que várias atitudes foram tomadas e que muito influenciaram e continuam presentes nos dias atuais, embora sendo algo tradicional, onde a violência a cada novo tempo, em diferentes fases de transformação do país, assumiu uma característica diferente, mas com o mesmo sentido, o de separar e conflitar a todos em qualquer situação.

Para explicar as diversas formas de violência pode-se afirmar que:

É problemático postular qualquer centralidade explicativa, seja ela, por exemplo, política, econômica, cultural. Ao evocar traços políticos ou culturais, tais como processo colonial, escravidão, tradição patriarcal, ou mesmo machismo, racismo etc., temos que levar em consideração que não há novidade nestas considerações, porém elas trazem o desafio de retirarmos delas as devidas consequências (RIFIOTIS, 2006, p. 2).

Ao discutir sobre violência no Brasil, é preciso ter um olhar bastante aguçado e reflexivo, a cerca de tantos fatos que levaram a uma violência crescente que atravessa gerações e épocas, que consome pessoas, que destrói famílias, gerando insegurança, corrupção, precisando desta forma, analisar tudo aquilo que trouxe essa "explosão" de atos condenáveis que se perpetua até hoje e que de certa forma, segundo estudiosos visto como uma coisa hereditária.

Assim, quando se menciona a hereditariedade, cita-se o contexto de uma das mais incessantes, sangrentas, cruéis e injustas lutas, que foi a escravidão no Brasil

\footnotetext{
${ }^{6}$ Instituição cuja função é executar as medidas socioeducativas aplicadas pelo Poder Judiciário aos adolescentes autores de atos infracionais com idade de 12 a 21 anos incompletos, conforme determina o Estatuto da Criança e do Adolescente (ECA).

${ }^{7}$ Autarquia funcional cuja função é executar as medidas socioeducativas aos adolescentes autores de atos infracionais cometidos com idade 18 anos incompletos. Atualmente chamada de FUNDAÇÃO CASA.
} 
e que virou uma verdadeira guerra pela continuação de fazer de seres humanos negros, animais sem autonomia para nada e assim, lutas e mais lutas para conquistar a liberdade.

E após uma grande persistência, foi supostamente abolida, depois de muitos anos em 1888, após muito tempo de práticas e conduções violentas, a sociedade brasileira, no final do século XIX, suscitou diversas expectativas em relação à modernização do país e ao projeto de nação, neste período ainda não se questionava direitos sociais ou direitos humanos. A violência em suas diferentes esferas parece ser algo embutido, enraizado nas pessoas e refletem infelizmente o cenário de uma sociedade que se encontra excessivamente brutal e cruel, onde a banalização se tornou frequente entre todos, pois:

\begin{abstract}
A violência gera o medo, mas este gera igualmente violência. Trata-se então de um círculo vicioso que se instala, uma psicose coletiva que é preciso romper a qualquer preço e cujos únicos beneficiados são certos lobbies da segurança, como as firmas de vigilância, as milícias privadas, as companhias de seguros, os esquadrões da morte, etc (CHESNAIS, 1999, p. 2).
\end{abstract}

De mínimas discussões que resultam em mortes, até de grandes movimentos geradores que mobilizam toda uma população, sejam com protestos, com organizações que prejudicam os menos favorecidos e ainda seja principalmente nos meios políticos onde cada um visa os seus próprios interesses e são capazes de cometer os piores atos em busca de alcançar seus objetivos sem pensar em quem o que poderá prejudicar.

\title{
Sociedade de Consumo
}

Atualmente, vivemos numa sociedade cada vez mais individualista, capitalista onde cada um busca alcançar seus objetivos, e o sentimento de união, cooperatividade e solidariedade, vem se tornando gradativamente mais escasso, frente à necessidade que as pessoas sentem em grande parte de se realizar profissionalmente, ter uma vida financeira estabilizada, e vivem sempre correndo para ter, aumentar e enriquecer ou pelo no mínimo chegar perto disso, ou seja, o ter é mais importante do que o ser. Desta forma, pode-se compreender que tanto o Brasil, como o mundo, vivem uma intensa luta pela vontade e necessidade cada vez mais feroz de consumir, e se flexibilizar de maneira a garantir um futuro considerado estável para si e demais gerações da sua descendência. 
Isso é o que podemos chamar de Sociedade de Consumo, termo que se tornou bastante popular e diariamente utilizado ao que se referem os avanços produtivos ao sistema capitalista, que ganharam mais força ao decorrer do século $\mathrm{XX}$, principalmente nos Estados Unidos que ao decorrer dos tempos foi crescendo pelo mundo e continua a se espalhar. Percebe-se que:

\begin{abstract}
A sociedade de consumo consegue tornar permanente a insatisfação. Uma forma de causar esse efeito é depreciar e desvalorizar os produtos de consumo logo depois de terem sido alcançados ao universo dos desejos do consumidor. Uma outra forma, ainda mais eficaz, no entanto, se esconde da ribalta: o método de satisfazer toda necessidade/desejo/vontade de uma forma que não pode deixa de provocar novas necessidades/desejo/vontades. O que começa como necessidade deve terminar como compulsão ou vicio (BAUMAN, 2007, p. 106)
\end{abstract}

A sociedade de consumo ajuíza e pondera os indivíduos por seus desempenhos e capacidades relacionadas ao consumo. Desta maneira, pode-se compreender que o desenvolvimento econômico e social vem a ser pautado pelo aumento do consumo, que resulta em lucro ao comércio e às grandes empresas, fazendo que haja o crescimento de uma maior oportunidade de empregos, aumentando a renda, o que acarreta ainda mais consumo.

Uma crise nesse modelo representaria um colapso, pois a renda diminuiria, o desemprego elevar-se-ia e o acesso a elementos básicos seria mais dificultado. Desta maneira, a sociedade de consumo também recebe muitas criticas, à medida que se fala além de uma grande perspectiva econômica. Mas também as consequências por diversos fatores ao meio ambiente, já que o consumismo desenfreado que se relaciona diretamente com a exploração indevida dos recursos naturais para obter-se matéria prima para a fabricação em larga escala de mercadorias refletem-se na destruição cada vez maior da natureza e diversas espécies na fauna e flora, causando danos muitas vezes irreversíveis.

Tudo isso fruto de um mundo não somente capitalista materialista e onde em especial no Brasil, as leis geralmente não são cumpridas e as próprias autoridades responsáveis, sendo que uma grande parcela se deixa corromper, ao permitir-se aceitar propostas em beneficio próprio.

O grande problema é que o homem do humanismo, aquele que vivia em harmonia com a natureza e com seus semelhantes, no seio de instituições cuja tutela não discutia, sobreviveu. Agora a necessidade se libertou da natureza, 
engendrando no homem uma paixão de possuir e um espírito de ambição que alimenta, por sua vez, a corrida ao poder, e:

Transbordando os limites da necessidade natural, o interesse prolifera e contamina rapidamente todo o tecido social. As instituições que tinham tradicionalmente a tarefa de contê-lo se apresentam, contudo, como os instrumentos de uma vasta manipulação, tendendo a manter o poder dos mais fortes (SOËTARD, 2010, p. 28).

Assim, a chamada sociedade de consumo é claramente calçada no crescimento do consumismo na sociedade para manter a circulação de capitais e garantir a geração de lucro. Desta forma, para melhor entender sociedade de consumo, a mesma diz respeito a uma nova época, onde preza o capitalismo e lucratividade, na perspectiva de uma atividade comercial cada vez mais ativa e gerando além do lucro, onde um dos fatores que ajudam para que tudo isso aconteça, os avanços tecnológicos, onde o meio publicitário que tem a função de divulgar indústrias fabrica e marcas de produtos, possuem papel essencial para que muito disso se concretize.

O desenfreado crescimento do consumismo, diante de uma sociedade que se torna gradativamente globalizada, representou também grandes mudanças dentre um delas pode-se citar o homem com uma transformação imensa e considerada negativa, já que o seu contato com a natureza e o apoio das instituições na continuação da cultura do consumo fez com que os homens acreditassem ser senhores de si, independentes e alheios aos demais e ao ambiente a sua volta, uma vez que:

O poder de escolha do indivíduo na esfera do consumo nas sociedades pós-tradicionais tem sido campo de debate sobre a sua real liberdade de escolha ou submissão a interesses econômicos maiores que se escondem por trás do marketing e da propaganda. Será o consumo uma arena de liberdade e escolha ou de manipulação e indução? Terá o consumidor efetivamente escolha? Ele é súdito ou soberano, ativo ou passivo, criativo ou determinado? (BARBOSA 2004, p. 35).

É possível perceber que o consumismo exorbitante em vários setores da sociedade como algo que negativamente influencia as pessoas ao hábito desordenado de querer ter, possuir e que as levam a se envolver em situações que fogem a aceitação vista como "normal", em nossa contemporaneidade, podendo assim, se tornarem reféns de uma nova maneira de viver em sociedade.

Pode-se compreender ou ainda interpretar certa manipulação que possivelmente poderá levar estas pessoas inconscientemente a não ter direito a 
escolhas e sim a seguir um estereotipo de vida, que desencadeia uma serie de questionamentos e posicionamentos por parte de muitos estudiosos, já que estes buscam sempre analisar, observar e compreender a sociedade e suas transformações ao longo dos tempos, bem como seu comportamento no cotidiano em diversos lugares, meios e situações.

Diante do contexto em questão, e levando em conta as constantes mudanças no cenário que tange sociedade, podemos citar a família que se situava tradicionalmente era vista e constituída numa residência, em um espaço, com todos os membros residindo no mesmo lugar. Atualmente, percebe-se a família com considerações transformações, onde é possível ver pais solteiros, filhos que fazem intercâmbio, bem como os meios de comunicação que tornam o contato quase que instantâneo. Sendo que esta instituição não precisa mais estar agrupada, e isto a fortalece. Isso ocorre com todas as instituições, seja a família, a religião, o Estado, etc. Pode-se comentar que:

A mudança nesse padrão tem resultado em novos e surpreendentes quebra-cabeças familiares: filhos de pais que se separam, e voltam a se casar, vão colecionando uma notável rede de meios-irmãos, meias-irmãs, avós, tios e pais adotivos (GRANATO e DE MARI, 1999, p.269).

Dentre as mudanças, decorrentes frente à busca incessante de se ter mais e mais, podemos também atribuir inúmeras críticas relacionadas a isso, sendo uma delas a adolescência, onde vem a ser uma fase que diretamente é fácil de influenciar, e existe uma preocupação diária pela aparência em todos os sentidos, principalmente em se vestir bem, ser admirado (a) e possuir bens que se tornaram característicos diante de uma nova época em que os hábitos e fases de desenvolvimento humano tomam uma nova roupagem, diante de um novo contexto inovador, idealizador e consumista na estratégia de produção de bens com prazo de validade determinado, para que o comprador usufrua e o descarte o mais rápido possível.

Estratégia que leva ao crescimento do consumo. Entretanto, decorrente da amplitude do consumo, há a expansão da produção de lixo, elevando com isso, danos ambientais oriundos desse meio.

\section{A Violência Contra Crianças e Adolescentes}


Atualmente no país, é possível perceber no cotidiano e através dos meios de comunicação, o crescente número da violência contra as crianças e adolescentes, que se manifestam de diferentes formas, desde agressões físicas, passando pela exploração sexual e até mesmo ao trabalho escravo destes, sendo tudo e outros demais existentes considerado crime, previsto em lei.

Dentre as violências já supracitadas, percebe-se que o primeiro ato contra esta geralmente parte da própria família, daqueles que possuem a função de guardar, educar, zelar para que a criança/adolescente tenha uma infância sadia e uma boa orientação.

A iniciação da sua fase adulta, com maus tratos dos mais variados tipos, e o abuso sexual de meninas e meninos indefesos que por muito tempo são usados como objetos e se tornam reféns destes indivíduos que os mantem nesta situação através de constantes ameaças causam traumas que jamais serão esquecidos e consequentemente os transformam em jovens e adolescentes revoltados, de difícil compreensão por demais pessoas e provavelmente adultos que terão diversos conflitos em todos os ambientes que irão transitar, seja na própria família, relacionamentos pessoais e profissionais. Diante da primeira violência que essas crianças e/ou jovens sofrem, podemos destacar a intrafamiliar que:

Na definição de violência intrafamiliar destacam-se dois aspectos: o primeiro
é de que se trata de uma violência interpessoal perpetrada, no caso das
crianças e adolescentes, por pessoas investidas de função parental. O
segundo aspecto ressalta que é uma violência cuja prática não se restringe
ao espaço doméstico, ou seja, a violência intrafamiliar contra crianças e
adolescentes é por vezes cometida pelos pais e responsáveis também em
espaços públicos (HAYECK, 2009, p. 63).

Diante da violência intrafamiliar, geralmente são situações que ocorrem no cotidiano familiar, onde se encontram em grande parte os pais que são apontados como responsáveis pela agressão, tendo a mãe também como agente ativo. Sendo em grande maioria as vítimas, crianças na faixa etária de zero a três anos destas situações, que em alguns casos termina com a morte destas. Percebe-se a existência de uma desproporção evidente neste tipo de crime, considerando a estrutura física de um adulto que não devemos nem comparar a de uma criança, uma vez que esta se torna vitima fácil para esse individuo, que ocasiona lesões físicas muitas vezes irreparáveis, utilizando até mesmo objetos domésticos para cometer tais agressões/crimes, que em si tendem a agravar as lesões. 
Após serem denunciados os responsáveis respondem a processo considerado crime e possivelmente acabam por serem penalizados e parar na cadeia por um determinado tempo a depender da gravidade do ato executado. A vítima por sua vez, terá o direito aos cuidados necessários e seus diretos serão preservados. A criança/adolescente, que passa por essa infeliz situação, geralmente é amparada, recebendo ajuda e apoio de terceiros, que recorrerá a uma instancia maior, ou seja, as autoridades responsáveis que buscar viabilizar tudo isso.

Desta forma, como as coisas e fatos estão relacionados entre si, pode-se então, trazer um pouco acerca do contexto histórico, que mostra muito a questão da violência domestica contra crianças e adolescente, já que desde antiguidade, a maneira de educar e buscar corrigir os filhos que praticavam atos condenáveis pelos pais para a eventual idade eram praticadas através das palmadas e surras, que sempre existiram em nossa sociedade.

Mas que ao passar dos tempos, tomaram uma proporção fora do contexto adequado, saindo da simples ação que consistia em solucionar erros de conduta e partindo para requintes de extrema crueldade, criando assim uma visão deturpada de educar e delimitar até onde essas crianças, jovens e adolescentes poderiam ir ou fazer algo.

Aquilo que era visto como educação, agora se transformou em violência contra a criança e o adolescente e cotidianamente podemos ver isso com frequência, onde perante as mudanças na concepção de família, também poderá ser um fator que de certa forma poderá ter contribuído para muitas coisas, inclusive essa transformação negativa em educar-se os filhos, ocasionando assim uma sociedade onde a marginalidade e criminalidade, cresce bastante, principalmente nas grandes cidades.

Frente a tantos atos que desrespeita a criança como um ser em formação, que precisa de atenção, cuidado e muito amor e carinho, para que estas se sintam protegidas, aconteceu a Convenção Internacional sobre os Direitos da Criança e Adolescentes, sendo aprovada em 20 de novembro de 1989, pela Assembleia Geral das Nações Unidas, a criação de uma lei, que visa proibir e punir castigos físicos, e dar à devida garantia de seus direitos humanos a criança/adolescente.

Desta maneira então perante a tudo isso, no país, foi criada a Lei no 8.069, de 13 de julho de 1.990, conhecido como o Estatuto da Criança e do Adolescente ECA, que tem a principal finalidade em garantir a proteção integral da criança e 
adolescente, oportunizando o seu crescimento, progresso físico, mental e social. O Estado tem a obrigação de proteger a todos, e desta forma não poderia ficar inerte, e assim possibilita cobrar e responsabilizar aquele que abusa do seu poder intrafamiliar, ou quem quer pratique um ato lesivo a integridade física, moral e social de uma criança/adolescente.

A proteção integral conferida ao menor por esses diplomas legais deve oportunizar prioritariamente suas necessidades inerentes ao desenvolvimento completo da personalidade, tendo em vista que a criança é um ser sem maturidade física e mental e necessita de proteção e cuidados especiais, inclusive a devida proteção legal (BRASIL, 1990).

Desta forma, com a criação do Estatuto da Criança e do Adolescente - ECA, o Brasil tornou-se referencia para os demais países na luta pela defesa de crianças e adolescência, e trouxe uma nova perspectiva para muitos destes que para fugir de maus tratos sofridos com frequência no seio familiar, acabavam por fugir indo para ruas, onde passavam fome e demais necessidades, acabando por cair no mundo das drogas, marginalidade e criminalidade, cada vez mais cedo. E sendo assim também crescente o numero de jovens que eram apreendidos e levados para casas de auxílios para estes, chamadas também de abrigos para menores infratores.

Garantir os direitos fundamentais da criança e do adolescente, com implementação de políticas públicas que deem condições de efetivação de seus direitos, cuidando daqueles que foram agredidos, e como forma preventiva para evitar novos casos de violência contra criança/adolescente, assim veio o ECA, e está vigente até os dias atuais. A Lei Ordinária ํㅜ 13.010, de 26 de junho de 2014, alterou a Lei 8.069, acrescentou alguns artigos, e, assim, estabelece-se que a criança/adolescente, deve ser educada sem a aplicação de castigos físicos, e ou tratamento cruel, que fira tanto a integridade física ou moral. Em um Estado Democrático de Direito, onde prevalece a democracia afirma-se que:

É precisamente a anexação de uma cláusula pétrea a um dado direito subjetivo o que melhor certifica a sua fundamentalidade, porque assim, ao declará-lo intocável e pondo-o a salvo inclusive de ocasionais maiorias parlamentares, que o poder constituinte originário o reconhece como um bem sem o qual não é possível viver em hipótese alguma (MARTINS NETO, 2003, p.88).

A criança e os adolescentes possuem seus direitos fundamentais e faz-se necessário garantir que pais, familiares, profissionais da educação, saúde, agentes 
públicos e qualquer outra pessoa que esteja incumbida de cuidar e educar, tratar com respeito e dignidade uma criança/adolescente.

Compreende-se que a violência contra o menor, ocorre primeiramente no ambiente familiar, e que seus principais agressores podem ser seus pais e irmãos, que são prisioneiros disto por muito tempo, devido a estarem sendo ameaçados constantemente e que não conseguem ter coragem suficiente para denunciar. $E$ quando isso ocorre os mesmos são ajudados por terceiros muitas vezes os vizinhos e que cabe às autoridades responsáveis buscar e encontrar os autores deste crime e puni-los da forma correta prevista em lei, pois:

A violência doméstica acontece contra crianças, adolescentes, mulheres e idosos, sendo que os agressores são os próprios familiares das vítimas. Um dos grandes fatores que favorecem a violência física, como os espancamentos, é a personalidade desestruturada para um convívio familiar do agressor, que não sabe lidar com pequenas frustrações que essas relações causam no decorrer do cotidiano (BARROS, 2016, p. 71).

Sendo que esta violência domestica, já pode ser visto como algo que acontece há muito tempo, presente na linha histórica da sociedade, e ainda que apesar de ser a primeira violência cometida - a familiar- mas pode acontecer também através de um possível amigo (a) da família, na escola, ou seja em qualquer ambiente, a criança ou adolescente não esta livre disso, e geralmente as pessoas as quais mais se se confiam, são as que cometem esses atos condenáveis e injustificáveis.

\section{Causas e Consequências da Violência na Formação Social}

Ultimamente está cada vez mais crescente e incontrolável a violência em diversos aspectos, sendo o Brasil, segundo algumas pesquisas um dos países onde acontecem mais homicídios provenientes da violência, em especial todo tipo desta praticado contra a mulher, configurando assim o feminicidio.

Mas a violência, de maneira ampla atinge a sociedade em diferentes esferas e vários níveis, indo da criança ao adulto mostrando assim um cenário brasileiro complicado em compreender, difícil de aceitar, já que acaba por cair numa rotina frequente, ocasionando reflexões acerca de quais os motivos que levam indivíduos inseridos numa sociedade com liberdade de ir e vir, cometer atrocidades e interromper ciclos, destruir sonhos e prejudicar a si próprio.

Neste aspecto esses indivíduos transforma também a forma de pensar e agir abalando de maneira direta e profunda em grande parte o aspecto psicológico e 
emocional das pessoas que passaram por esta experiência cruel e que sobreviveram a tudo isso, sendo que, algumas vitimas conseguem resistir a muitas agressões físicas.

Algumas das causas que podem levar a essa série de agressões sendo elas: físicas e/ou psicológicas, podem ser o extinto que muitas pessoas possuem em dominar o ambiente em que se encontra e que todo ao seu redor seja submisso (a), outro pode ser a dependência social e principalmente financeira que interfere diretamente na convivência sendo que todos devem fazer o que for imposto.

A sociedade brasileira tradicional, a partir de um complexo equilíbrio de hierarquia e individualismos desenvolveu, associado a um sistema de trocas, reciprocidade na desigualdade e patronagem ${ }^{8}$, o uso da violência, mais ou menos legítimo, por parte de atores sociais bem definidos, pois:

Neste cenário social, a manipulação do poder, a corrupção e o uso da força, teve um papel fundamental na estruturação do sistema social da época, o que muitas vezes pode ter conduzido há uma legitimação velada destes atos na constituição da sociedade brasileira (VELHO, 2000, p. 57).

Entre os mais variados motivos que resultam na situação supracitada, compreende-se que o ponto principal poderá ser o ato da submissão na relação entre domínio e dominado, ocasionando momentos de medo, insegurança e inquietação.

Assim, é possível pensar também nas consequências, que podem ser devastadoras, fazendo desta forma, nascer uma nova sociedade embutida de revoltas, conflitos e impregnada de pessoas que dificilmente se sentirão felizes, realizadas e protegidas, tendo praticamente sempre desconfiança e mantendo distancia de qualquer pessoa que venha a se aproximar, uma vez que tudo o que venha sofrido causou grande traumas que muitas ainda venham a prevalecer por não ter tido um apoio e acompanhamento de profissionais adequados para preparar esta pessoa para a vida em sociedade.

Esses atos acabam por ser predominantemente insustentável na vida adulta com ações e atitudes que remetem um isolamento social que poderá a solidão e possível depressão. Assim, à aproximadamente há mais de um século, buscar-se formular propostas para diminuir a violência, punir os responsáveis consequentemente prende-los, resultando em índices cada vez piores.

\footnotetext{
${ }^{8}$ Apoio moral ou material oferecido por alguém ou por uma organização.
} 
Indivíduos que muitas vezes se tornam pessoas violentas, provavelmente já passaram em algum momento da sua vivencia por algum tipo de agressão que gerou sofrimentos insuperáveis e despertou um lado cruel e implacável, e que não ver qual erro em fazer com outras pessoas o que o fizeram da mesma maneira ou até pior.

Notamos famílias desestruturadas, onde a atenção, o amor e a segurança são essenciais para o desenvolvimento positivo dos indivíduos, compensando o que geralmente faltava, e também elementos necessários ao seu bom desenvolvimento, e diversos outros motivos que infelizmente agregava somente a violência, o ressentimento. Tudo isso influenciando pessoas que optam por seguir uma conduta considerada inadequada para viver em sociedade, onde ficaram marcados pela violação da sua autoestima, que o submeteu a episódios de violência física, mental, emocional, relacional e social (ADORNO, 2000).

Nessa perspectiva, infelizmente o que se presencia a cada no país e que deixam todos estarrecidos, são as consequências de uma infância não vivida como deveria, um juventude destruída e assim as falhas na formação da personalidade, que ocasiona mentalidades doentias, levando a um perfil criminoso. Infelizmente, na sociedade ainda prevalece o cruel preconceito com relação à pobreza e as desigualdades sociais sejam as principais causas no surgimento e aumento contínuo da criminalidade. Pode-se defender que:

Não são suficientes a redução das desigualdades sociais ou a intensificação
do controle ou repressão, o tratamento democrático ao avanço da
criminalidade urbana depende da institucionalização de um regime jurídico
pluralista, baseado em princípios de avaliação e julgamento cujo valor
fundamental deve ser a vida, e não a liberdade (Ibid., p. 140).

Algo que vemos que não vem a ser desta forma, sendo que constantemente em nossa sociedade nos deparamos com diversos casos de criminalidade ocorrida com pessoas consideradas de classe média alta, e de forma assustadora onde, por exemplo, filhos planejam a morte dos pais, matam toda a família, entre outros atos que geram medo. Portanto, as causas que geram a violência não poderá ter um estereotipo, bem como as condições de vida não poderá ser apontada com a mola propulsora da violência, bem como poderá estar em qualquer lugar.

Por consequência, combatendo-se a pobreza, os indicadores da violência diminuiriam. Terrível engano. Os pobres não são agentes e, sim, as maiores vítimas. Assim, a maior parte dos moradores em favelas, é constituída de cidadãos honestos, 
trabalhadores, que sofrem em sua convivência diária com situações de risco. Vale lembrar, não devemos confundir favelas com celeiro de marginais. Existe uma mão de via dupla, onde poderá existir violência em qualquer um dos lados, tanto nos considerados pobres como nos tidos como ricos. E as consequências são facilmente visíveis em nosso cotidiano, podendo ter inúmeros motivos que resultaram nesta difícil realidade, pois a violência pode ser compreendida como uma doença psicossocial.

Diante das causas, na maioria das vezes, as consequências da ação de indivíduos portadores de sérios distúrbios comportamentais, derivados, principalmente, de transtornos afetivos graves com suas raízes na primeira infância, ocasiona gerar para a sociedade indivíduos totalmente conflitantes e propícios a ser intolerantes, com extinto agressivo e desconfiado de tudo e todos (MINAYO, 2010).

Isso pode resultar a entrada dos indivíduos no submundo da criminalidade, onde a lei da sobrevivência é cruel e avassaladora, sendo o retrato de qualquer ato ocorrido anteriormente em sua vida e que poderá ter levado a isso, muitas vezes pode ser visto como contraditório já que em alguns momentos classe social não interfere na formação da personalidade de cada pessoa, onde algum possivelmente já nasce com traços de instintos negativos e ao passar do tempo só vai se acentuando.

\section{Considerações Finais}

A violência, mesmo com tantas leis, as quais não são respeitadas e cumpridas por uma grande parte, a mesma é algo que vem sendo cada vez mais difícil em ser combatida, já que os primeiros erros e injustiças são cometidos por aqueles deveriam segui-las e fazer valer a sua autoridade de forma responsável e correta.

Falando também das mesmas leis destaca-se que elas beneficiam uma grande parcela dos favorecidos, enquanto os demais pelos simples fato de ser financeiramente fracos, residirem em lugares considerados perigosos, portanto, imperando o preconceito que insiste em viver entre nós. Ou seja, a injustiça, escravidão e superioridade nunca deixaram de existir só mudaram de nome e endereço e a violência, portanto, sendo consequência de tudo isso, frente aos sentimentos negativos que geram em muitas pessoas que sofrem com tudo isso. 
As causas da violência podem ter várias e as consequências na formação social são de consideráveis danos ao indivíduo, trazendo para todos transtornos gravíssimos, desestruturando famílias, grupos ou toda uma sociedade, refletindo assim um país que ainda precisa rever muita coisa, na assistência as famílias, atenção a sua população e combate a visão deturpada que ainda impera na grande parcela dos indivíduos.

As inúmeras práticas violentas começaram a ser discutidas a partir do século XIX. Em nosso país, as manifestações de violência começaram a ser mais debatida principalmente a partir da década de 1980 e ao decorrer dos anos até os dias atuais, continua ser estudada, já que cada vez mais mostra o perfil de pessoas que geralmente não seriam capazes de tanta crueldade, levando a ser considerado um distúrbio de comportamento, provenientes de alguma violência que possivelmente tenha sofrido também.

Fenômenos sociais que eram considerados marginais ou secundários nos países avançados, mas típicos dos países em desenvolvimento (exclusão social, violência endêmica, marginalidade, pobreza) reaparecem como fenômenos não do pré-modernidade, mas da pós-modernidade. O mundo, apesar das enormes diferenças e disparidades de recursos entre os países, passou a partilhar incertezas similares em relação ao futuro.

\section{Referências:}

ADORNO, S. Exclusão socioeconômica e violência urbana. Porto Alegre: Ver.Sociologias, 2000.

BARROS, J. Violência Doméstica. São Paulo: Brasil Escola, 2016

BAUMAN, Z. Vida Liquida. Rio de Janeiro: Jorge Zahar, 2007.

BARBOSA, L. Sociedade de consumo. Rio de Janeiro: Jorge Zahar Editor, 2004.

BRASIL. Lei no 8.069. 13 de Julho de 1990. Brasília: MEC, 1990. Atualizado e comentado. Disponível em: http://www.direitocom.com/estatuto-da-crianca-eadolescente-comentado/titulo-i-dasdisposicoes-preliminares-do-artigo-10-ao6o/artigo-1. Acesso em: 10 dez. 2019

CECCON, C. Definições de Violências. Paraná: Semana Pedagógica, 2009.

CHESNAIS, J. C. A violência no Brasil: Causas e recomendações políticas para a sua prevenção. Rio de Janeiro: Ciênc. saúde coletiva, 1999. 
DOS SANTOS BARROS, C. R.; SCHRAIBER, L. B. Violência por parceiro íntimo no relato de mulheres e de homens usuários de unidades básicas. [s.l.]:Revista de Saúde Pública, 2017.

FERMOSO, P. La violência en la escuela: El educador -pedagogo social escolar. In PANTOJA, L. (Org.). Nuevos espacios de laeducación social. Bilbao. [s.I.]:Universidad de Deusto, 1998

GRANATO, A.; DE MARI, J. Os meus, os seus, os nossos. São Paulo: Rev. Veja, 1999

HAYECK, C. M. Refletindo sobre a violência. São Paulo: Revista Brasileira de História \& Ciências Sociais, 2009.

HOUAISS A. O Grande Dicionário Houaiss da Língua Portuguesa. Rio de Janeiro, 2001

KRUG, E.G. et al. World report on violence and health. Geneva: World Health Organization, 2002.

MARTINS NETO, J.P. Direitos fundamentais: conceitos, função e tipos. São Paulo: Revista dos Tribunais, 2003.

MINAYO, M.C.S. Violência social sob a perspectiva da saúde pública. Rio de Janeiro: Departamento de Ciências Sociais da Escola Nacional de Saúde Pública, 2010

MODENA, M. R. Conceitos e formas de violência [recurso eletrônico]: / org.. Caxias do Sul, RS: Educs, 2016

RIFIOTS, Theophilos. Nos campos da violência: diferença e positividade. Disponível em: Laboratório de Estudos da Violência - CFH/UFSC, Florianópolis, 2006. Acesso em: 21 dez 2019.

RUS PEREZ, J.R.; PASSONE, E. F. Políticas Sociais de Atendimento às Crianças e aos Adolescentes no Brasil. [s.l.]:Cadernos de Pesquisa, v.40, n.140, maio/ago. 2010

SOËTARD, M. Jean-Jacques Rousseau e o Processo Educacional de Formação do Homem na Sociedade. Tradução de Verone Lane Rodrigues. Recife: Fundação Joaquim Nabuco, Editora Massangana, 2010. Disponível em: <http://www.dominiopublico.gov.br/download/texto/me4675.pdf>. Acesso em: 16 maio 2018.

VELHO, G. O desafio da violência. São Paulo: Estudos Avançados, 2000.

YUS, R. Educação Integral: uma educação holística para o século XXI. Porto Alegre: Artmed, 2002. 